\title{
Determinants and effects of positive surgical margins after prostatectomy on prostate cancer mortality: a population-based study
}

\author{
Valesca P Retèl ${ }^{1}$, Christine Bouchardy ${ }^{1}$, Massimo Usel ${ }^{1}$, Isabelle Neyroud-Caspar ${ }^{1}$, Franz Schmidlin², Gregory Wirth ${ }^{3}$,
} Christophe Iselin $^{3}$, Raymond Miralbell ${ }^{4}$ and Elisabetta Rapiti ${ }^{*}$

\begin{abstract}
Background: The objective of this population-based study was to assess patient, physician and tumour determinants associated with positive surgical margins after prostatectomy, and to assess the effects of positive surgical margins on prostate cancer-specific survival.

Methods: We included 1'254 prostate cancer patients recorded at the Geneva Cancer Registry who had radical prostatectomy during 1990-2008. To assess factors associated with positive margins, we used logistic regression. We assessed the effects of positive margins on prostate cancer-specific survival by Cox proportional hazard models accounting for numerous other prognostics factors including prostate and tumour volume, the total percentage of tumour, radiotherapy, surgical approach and surgeon's caseload.

Results: Among men undergoing prostatectomy, 479 (38\%) had positive margins. In the multivariate logistic regression analysis, period, clinical- and pathological T stage, Prostate Specific Antigen (PSA) level, Gleason score and percentage of tumour in the prostate were significantly associated to positive margins. Ten-year prostate cancer-specific survival was 96.6\% for the negative margins group and $92.0 \%$ for the positive margins group (log rank $p=0.008$ ). In the Cox survival analysis adjusted for tumour characteristics, surgical margin status per se was not an independent prognostic factor while age, pathological T, PSA level and Gleason score remained associated with prostate cancer-specific survival.
\end{abstract}

Conclusions: More aggressive tumour characteristics were strong determinants for positive margins. Furthermore, surgical margin status per se was not an independent prognostic factor for prostate cancer-specific survival after adjusting by the gravity of the disease in the multivariate analysis.

Keywords: Prostate cancer, Prostate cancer-specific survival, Prostatectomy, Surgical margins

\section{Background}

Prostate cancer is the second most frequently diagnosed cancer and the fifth most common fatal cancer among men worldwide, the fourth for developed countries [1]. A high percentage of men are diagnosed with early stage disease due to the spontaneous generalization of prostate specific antigen (PSA) screening [2]. Radical prostatectomy is the main treatment option for clinically localized prostate cancer, as shown by the randomized Scandinavian prostate Cancer Group Study Number 4 (SPCG-4)

\footnotetext{
* Correspondence: elisabetta.rapiti@unige.ch

${ }^{1}$ Geneva Cancer Registry, Global Health Institute, University of Geneva, 55 Bd. de la Cluse, Geneva 1205, Switzerland

Full list of author information is available at the end of the article
}

[3]. However, as shown recently by Wilt et al., the difference between radical prostatectomy and watchful waiting was not significant [4]. Positive surgical margins (PSMs), identified as the presence of cancer at the inked resection margin of the prostatectomy specimen, are a relatively frequent finding after prostatectomy and reported in many articles with proportions ranging from 10 to 40\% [5]. Although there are many reports and studies available, questions remain regarding determinants and effects of PSM. Furthermore, in relation to survival, surgical margins are the only factor which could be influenced by the surgeon, contrary to tumour characteristics.

Some investigations have correlated patient, clinical and histo-pathological findings with surgical margin status 
after prostatectomy [6-8]. Coelho et al., investigated several determinants of surgical margins, such as type of surgery, location of PSM, prostate weight and tumour volume [6]; Williams et al., investigated determinants such as period of surgery, geographical region, type of surgery and surgeon caseload [7]; and finally Vesey et al., studied surgeon caseload and prostate weight [8]. They all found that the tumour characteristics such as clinical stage, pathological stage, Gleason score and the percentage of tumour in the prostate were more often significantly associated with surgical margin status.

Furthermore, several studies have investigated the association between surgical margins and outcome after radical prostatectomy [9-17]. Two types of outcomes are usually described in this context; either PSA biochemical recurrence (BCR) through routine serum PSA monitoring every six months after treatment, and/or prostate cancer-specific survival (PCSS). PSM after radical prostatectomy is known to be an independent risk factor for BCR; however, there is no wide consensus on its impact on survival [14-16]. Although most studies reporting on BCR show significant association with PSM [9-12], studies reporting on PCSS show mostly non-significant association with PSM [13-17].

The aim of the present study was twofold; 1 ) to assess patient, physician and tumour characteristics associated with PSM after prostatectomy, and 2) to assess if PSM is an independent prognostic factor for prostate cancerspecific mortality (PCSS).

\section{Methods}

\section{Patients}

We included 1'254 patients diagnosed with prostate cancer between 1990 and 2008 who underwent radical prostatectomy using data from the Geneva Cancer Registry in Switzerland.

\section{Variables}

The Geneva Cancer Registry records all incident cancers occurring in the population of the canton (approximately $475^{\prime} 000$ inhabitants in 2009). All hospitals, pathology laboratories, and practitioners are requested to report all cancer patients. Trained registrars systematically abstract data from medical and laboratory records. Physicians regularly receive questionnaires to obtain missing data. Recorded data include various information on patient and tumour characteristics, treatment and outcome. The Registry regularly assesses survival data. Active follow-up is performed yearly using the files of the Cantonal Population Office which is in charge of registration of the resident population. The registrars establish cause of death by systematically consulting clinical records and interpreting questionnaires completed by the patient's physician. In general, the Registry records data on treatments given during the first six months, however for this study we re-opened all files and collected all treatment data. The patients were followed for vital status up to $31^{\text {rst }}$ December 2011.

As variables of interest, we considered age in continuous or categorical $(<60,60-69, \geq 70$ years $)$, period at diagnosis (1990-4, 1995-9, 2000-4, 2005-8), socioeconomic status based on last patient's occupation (high, middle, low, unknown), sector of care (private, public), method of detection (screening by PSA, symptoms, other), and surgeon caseload (the mean of prostate cancer surgeries that the surgeons performed). For surgical approach we considered "open" procedures (perineal and retropubic), laparoscopic and robot assisted laparoscopic surgeries. Because before 1998 laparoscopic and robot assisted prostatectomies were not performed in Geneva, we classified the "unknown" procedures before 1998 as "open" surgical procedures. Adjuvant radiotherapy was given in adjunction (within one year) to prostatectomy, without signs of PSA raise. Salvage radiotherapy was given only after PSA raise or other signs of local recurrence. In the analyses, the variable radiotherapy includes both those patients with adjuvant radiotherapy and those with salvage radiotherapy. In case radiotherapy was accompanied by hormonal therapy, this was included in the radiotherapy category.

All specimens were analysed by one of the three pathology laboratories existing in Geneva; one public and two private. The presence of tumour cells at the inked margin of the resection was considered to represent a PSM. A "close" surgical margin was considered as tumour cells in close proximity to the ink (within $1 \mathrm{~mm}$ from the inked margin), according to Chuang and Epstein [18]. Besides the surgical margin status, other tumour characteristics were considered such as clinical stage (cT0-cT1, cT2, cT3, cTx (unknown) and pathological stage (pT1-2, pT3T4) [19], PSA value at diagnosis $(<10 \mathrm{ng} / \mathrm{ml}, 10-20,>20)$, Gleason score (Gleason $<7$, Gleason $=7$, Gleason $>7$ ), margin extension as focal (unifocal and $<=3 \mathrm{~mm}$ ) and extensive (plurifocal and $>4 \mathrm{~mm}$ ), and tumour percentage in the prostate. The volume of the prostate and of the tumour were measured by multiplying the largest height, width and length by $0.524(H \times W \times L \times \pi / 6)$, according to Bates et al. [20] Tumour percentage of the prostate was calculated as tumour volume divided by the prostate volume. As capsular extension was highly correlated with pathological T status (intracapsular $=$ pT1-2, extracapsular extension $=$ pT3-4), we did not include this variable in our analysis.

\section{Statistical analysis}

We performed a case-control study, considering patients with PSM as cases and patients with negative surgical margins as controls. We used the $\chi^{2}$ test and univariate 
and multivariate logistic regression to assess the relationship between surgical margins and other variables. Tenyear prostate cancer survival curves according to surgical margins status were estimated by means of Kaplan Meyer methods, and survival differences were tested through log rank test. We used Cox proportional regression analyses to assess the independent effect of surgical margins on ten-year prostate cancer-specific survival after radical prostatectomy while adjusting for other prognostic factors as assessed in univariate analysis. In the logistic and Cox regressions we regrouped negative-and close surgical margins together for further analyses as suggested in the literature [21]. The statistical significance level was set at $p$ value $<0.05$. Stepwise backward elimination was used to reduce the model to factors with $\mathrm{p}<0.10$. Statistical analysis was performed using the software Statistical Package for Social Sciences (SPSS version 15.0, Chicago, IL).

All data analysis was conducted at the Geneva Cancer registry. As a cancer registry we do not require Ethical permission and accordingly no informed consent is required for registry-based studies involving no contact with the study subjects. The Registry has a general authorization, provided by the Federal Expert Commission in charge of data protection, to collect nominative data for research purposes on cancer in the general population.

\section{Results}

\section{Association between patient and tumour characteristics and post-operative surgical margins}

Among the 1'254 prostate cancer patients undergoing prostatectomy, 479 (38.2\%) had PSM, 629 (50.2\%) negative surgical margins and 146 (11.6\%) close surgical margins. We observed that the most common location of PSM was at the apex (53.9\%) and the posterior (19.0\%) of the prostate (data not shown).

Table 1 presents the distribution of patient characteristics, tumour characteristics, and treatment according to surgical margins and the Odds Ratios (ORs) derived from the univariate logistic regression. The patients with negative and close margins were considered together in the category negative margins. The mean age at diagnosis was 63 years (Standard deviation [SD] \pm 6.3 years) and did not differ between the two groups of surgical margins. The PSM rate decreased over time, from 50\% in 1990-1994 to $31 \%$ in $2005-2008$ (test for trend $\mathrm{p}<0.001$ ). Most patients were treated in the private sector (64.1\%). The majority of the patients were diagnosed through screening (83.4\%). Close surgical margins were more often reported by the private pathology laboratories compared to the public ones $(71.9 \%$ and $28.1 \%$ respectively, $\mathrm{p}=0.049)$. The information about lymph node dissection was available only since 1999. Among the 1023 patients for whom we had the information, 374 (37\%) had a lymph node dissection, and of these 347 were free of metastasis (214 in the negative and 133 in the positive margin group). In terms of PSM rates were higher after the open surgical procedures $(196 / 427,45.7 \%)$ compared to robot-assisted prostatectomies $(35 / 109,32.1 \%)(\mathrm{p}=0.010)$. Among the 479 patients with PSM, 32 (7\%) received adjuvant radiotherapy, and 124 (26\%) received salvage radiotherapy. For the patients with negative surgical margins, adjuvant radiotherapy was given to only 3 of $775(0.4 \%)$ patients, and 30 (4\%) received salvage therapy. In the univariate analysis, all tumour characteristics such as clinical and pathological T-status, PSA level, Gleason score, prostate volume, tumour volume and percentage were significantly associated with PSM.

Table 2 presents the results from the multi-adjusted logistic regression model. All factors significantly associated with PSM in the univariate analysis were simultaneously entered in the model. Clinical and pathological $\mathrm{T}$ status were entered into two separate models, due to their high co-linearity, the results presented derive from the model with clinical $\mathrm{T}$ status. The following factors remained significantly associated with PSM: period of diagnosis, clinical T3 status compared to the cT0-1 reference category (Odds Ratio (OR) 1.73, 95\% Confidence Interval (CI) $1.05-2.85 ; \mathrm{p}=0.031$ ), pathological T3-4 status compared to the reference category pT0-2 (OR 2.68; 95\% CI 2.00-3.59; $\mathrm{p}<0.001)$, PSA level 10-20 and $>20$ compared to the reference category $<10$ (OR 1.52, 95\% 1.06-2.17; $\mathrm{p}=0.023$, and OR $1.80,95 \% 1.06-3.05 ; \mathrm{p}=0.029$, respectively), Gleason score 7 and 8-10 compared to the reference category 2-6 (OR 1.61, 95\% 1.23-2.12; $\mathrm{p}=0.001$ and OR $2.25,95 \% 1.39-3.63 ; \mathrm{p}=0.001$, respectively), and tumour percentage $\geq 10 \%$ compared to the reference category of $<10 \%$ (OR 2.90; 95\% CI 2.21-3.81; p < 0.001).

\section{Association between post-operative surgical margins and prostate cancer-specific survival}

During the follow-up period, 141 of the 1,254 men died (11\%) including 51 (4\%) from prostate cancer. Patients lost to follow-up were $153 / 1,254(12.2 \%)$. The mean follow-up time was 6.9 years and the median time was 6.1 years (range two months-20 years). Ten-year PCSS was 96.6\% (95\% CI: 94.3-98.8) for the negative surgical group, and $92.0 \%$ (95\% CI: 88.5-95.4) for the PSM group $(\log$ rank $\mathrm{p}=0.008)$ (Figure 1$)$. Within the negative group the 10-year survival of patients with a truly negative margin was 97.1\% (95\% CI: 94.6-99.5) and that of patients with close margins was $94.5 \%$ (95\% CI: 88.8-99.9). In the univariate Cox analysis, surgical margin status, age, surgeon caseload, pathological T-stage, PSA level, Gleason score and tumour percentage were significantly associated with prostate cancer-specific survival (Table 3). In the multivariate Cox regression including the entire set of variables tested in crude analysis and using stepwise backward elimination, age, pathological T-status, PSA 
Table 1 Comparison $^{\mathrm{a}}$ of sociodemographic, treatment and surgeon characteristics among prostate cancer patients after prostatectomy $(n=1$ '254) according to surgical margin status

\begin{tabular}{|c|c|c|c|c|c|c|c|}
\hline \multirow[t]{4}{*}{ Characteristics } & \multicolumn{4}{|c|}{ Surgical margin status } & \multirow{4}{*}{$\begin{array}{c}\text { Total } \\
\text { N }\end{array}$} & \multirow{4}{*}{$\begin{array}{l}\text { Crude } \\
\text { Odds rati } \\
(95 \% \mathrm{Cl})\end{array}$} & \multirow{4}{*}{$\mathrm{P}$-value } \\
\hline & \multirow{2}{*}{\multicolumn{2}{|c|}{$\begin{array}{c}\text { Positive } \\
\text { (cases) }\end{array}$}} & \multirow{2}{*}{\multicolumn{2}{|c|}{$\begin{array}{l}\text { Negative }^{\mathrm{b}} \\
\text { (controls) }\end{array}$}} & & & \\
\hline & & & & & & & \\
\hline & $\mathrm{N}$ & $\%$ & $\mathrm{~N}$ & $\%$ & & & \\
\hline Age Mean (SD) & 63.39 & $(6.00)$ & 62.94 & (6.48) & 63.12 & $(6.30)$ & 0.218 \\
\hline
\end{tabular}

Age class

$\begin{array}{lcccccc}<60 & 127 & 37.1 & 215 & 62.9 & 342 & 1 \\ 60-69 & 276 & 38.3 & 445 & 61.7 & 721 & 1.05(0.81-1.37) \\ \geq 70 & 76 & 39.8 & 115 & 60.2 & 191 & 1.12(0.78-1.61)\end{array}$

Period

$\begin{array}{lcccccl}1990-1994 & 29 & 50.0 & 29 & 50.0 & 58 & 1 \\ 1995-1999 & 105 & 42.9 & 140 & 57.1 & 245 & 0.75(0.42-1.33) \\ 2000-2004 & 201 & 40.8 & 292 & 59.2 & 493 & 0.69(0.40-1.19) \\ 2005-2008 & 144 & 31.4 & 314 & 68.6 & 458 & 0.46^{* *}(0.26-0.80)\end{array}$

Social class status

High

Middle

Low

Unknown

Sector of care

Private

Public

Method of detection

Screening

Symptoms

Other

394

Type of surgery

Perineal/Retropubic 196

Laparoscopic

Robot-assisted

Unknown

Surgeon caseload (number of prostatectomies)

$\begin{array}{lc}\text { High }(>50) & 379 \\ \text { Middle }(15-50) & 74 \\ \text { Low }(<15) & 24 \\ \text { Unknown } & 2\end{array}$

Radiotherapy with or without hormonal therapyc

$\begin{array}{ll}\text { No } & 325 \\ \text { Yes } & 154\end{array}$

Clinical T

CTO-CT1

$\mathrm{CT} 2$
$35.9 \quad 279$

$38.8 \quad 325$

40.8

38.5

38.8

37.1

37.7

44.3

37.8

$45.9 \quad 231$

39.2

32.1

33.2

37.6

44.6

32.0

33.3

30.5

82.4

\section{2}

33

31.8

35.7

$$
92
$$$$
51
$$$$
4
$$

178

293
64.1

61.2

59.2

61.5

61.2

62.9

62.3

55.7

62.2

54.1

60.8

67.9

66.8

$$
435
$$$$
531
$$$$
262
$$

1.13 (0.87-1.47)

$1.24(0.90-1.69)$

$1.12(0.50-2.52)$

$$
26
$$

.

$$
804
$$

1

0.93 (0.73-1.18)

$$
450
$$

1046

97

1

$1.32(0.87-2.01)$

111

1.01 (0.67-1.51)

$\begin{array}{ll}427 & 1 \\ 158 & 0.76(0.53-1.10) \\ 109 & 0.56^{*}(0.36-0.87) \\ 560 & 0.59^{* * *}(0.45-0.76)\end{array}$

$<0.001$

$\begin{array}{lcl}62.4 & 1007 & 1 \\ 55.4 & 166 & 1.33(0.96-1.86) \\ 68.0 & 75 & 0.78(0.47-1.29) \\ 66.7 & 6 & 0.83(0.15-4.55)\end{array}$

0.235

66.7

69.5

1067

187

10.65 (7.16-15.86)

$<0.001$

17.6

68.2

261

1

$<0.001$

$<0.001$

0.602

0.554

0.434

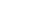

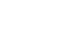

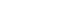

$64.3 \quad 456 \quad 1.19(0.86-1.65)$ 
Table 1 Comparison ${ }^{a}$ of sociodemographic, treatment and surgeon characteristics among prostate cancer patients after prostatectomy $(n=1 ' 254)$ according to surgical margin status (Continued)

\begin{tabular}{|c|c|c|c|c|c|c|c|}
\hline CT3 & 79 & 63.2 & 46 & 36.8 & 125 & $3.68^{* * *}(2.36-5.76)$ & \\
\hline cTx & 154 & 37.4 & 258 & 62.6 & 412 & $1.28(0.92-1.78)$ & \\
\hline \multicolumn{8}{|l|}{ Pathological T } \\
\hline рT0-pT2 & 239 & 27.5 & 629 & 72.5 & 868 & 1 & \multirow[t]{2}{*}{$<0.001$} \\
\hline pT3-pT4 & 240 & 62.2 & 146 & 37.8 & 386 & $4.33(3.36-5.58)$ & \\
\hline \multicolumn{8}{|l|}{ PSA level } \\
\hline $0-9$ & 217 & 32.8 & 445 & 67.2 & 662 & 1 & \multirow[t]{4}{*}{$<0.001$} \\
\hline $10-20$ & 98 & 51.0 & 94 & 49.0 & 192 & $2.14^{* * *}(1.54-2.96)$ & \\
\hline $21+$ & 57 & 64.0 & 32 & 36.0 & 89 & $3.65^{* * *}(2.30-5.80)$ & \\
\hline Unknown & 107 & 34.4 & 204 & 65.6 & 311 & $1.08(0.81-1.43)$ & \\
\hline \multicolumn{8}{|l|}{ Gleason } \\
\hline $2-6$ & 218 & 30.5 & 497 & 69.5 & 715 & 1 & \multirow[t]{4}{*}{$<0.001$} \\
\hline 7 & 195 & 45.2 & 236 & 54.8 & 431 & $1.88^{* * *}(1.47-2.41)$ & \\
\hline $8-10$ & 60 & 61.9 & 37 & 38.1 & 97 & $3.70^{* * *}(2.37-5.74)$ & \\
\hline Unknown & 6 & 54.5 & 5 & 45.5 & 11 & $2.74(0.83-9.06)$ & \\
\hline \multicolumn{8}{|c|}{ Prostate volume $\left(\mathrm{cm}^{3}\right)$} \\
\hline$\leq 60$ & 422 & 41.0 & 607 & 59.0 & 1029 & 1 & \multirow[t]{3}{*}{$<0.001$} \\
\hline$>60$ & 53 & 25.7 & 153 & 74.3 & 206 & $0.50^{* * *}(0.36-0.70)$ & \\
\hline Unknown & 4 & 21.1 & 15 & 78.9 & 19 & $0.38(0.13-1.16)$ & \\
\hline \multicolumn{8}{|c|}{ Tumour volume $\left(\mathrm{cm}^{3}\right)$} \\
\hline$\leq 10$ & 347 & 35.7 & 624 & 64.3 & 971 & 1 & \multirow[t]{3}{*}{$<0.001$} \\
\hline$>10$ & 58 & 70.7 & 24 & 29.3 & 82 & $4.35^{* * *}(2.65-7.12)$ & \\
\hline Unknown & 74 & 36.8 & 127 & 63.2 & 201 & $1.05(0.76-1.44)$ & \\
\hline \multicolumn{8}{|c|}{ Tumour percentage $^{d}$} \\
\hline$\leq 10 \%$ & 202 & 26.7 & 554 & 73.3 & 756 & 1 & \multirow[t]{3}{*}{$<0.001$} \\
\hline$>10 \%$ & 252 & 57.9 & 183 & 42.1 & 435 & $3.78^{* * *}(2.94-4.85)$ & \\
\hline Unknown & 25 & 39.7 & 38 & 60.3 & 63 & $1.80^{*}(1.06-3.07)$ & \\
\hline Total & 479 & 38.2 & 775 & 61.8 & 1245 & & \\
\hline
\end{tabular}

Geneva Cancer Registry 1990-2008.

${ }^{a}$ Crude logistic regression comparing patients with positive surgical margins (the cases) with those with negative surgical margins (the controls).

${ }^{\mathrm{b}}$ Negative and close.

${ }^{\mathrm{c}}$ Radiotherapy includes both salvage and adjuvant categories.

${ }^{\mathrm{d}}$ Tumour percentage of the prostate was calculated as tumour volume divided by the prostate volume

$\mathrm{Cl}$ : confidence interval.

${ }^{*} \mathrm{p}<0.05 ;{ }^{* *} \mathrm{p}<0.01$; ${ }^{* * *} \mathrm{p}<0.001$.

level and Gleason score remained significantly associated with PCSS (Table 3). Men in the age category 60-69 (HR 0.28 ; $95 \%$ CI $0.11-0.66 ; \mathrm{p}=0.004$ ) had a lower risk of mortality compared to the reference category of $<60$ years. Men with a pathological T3-4 status had a higher risk of mortality compared to the reference category pT0-2 (HR 2.61; 95\% CI 1.05-6.48; p=0.039), as well as men with PSA level greater than 21 (HR 2.89; 95\% CI 1.18-7.08; $\mathrm{p}=0.020)$ and a Gleason score $7(\mathrm{HR}$ 5.28; 95\% CI 1.67-16.7; $\mathrm{p}=0.005$ ), 8-10 (HR 22.53; 95\% CI 7.10-71.5; $\mathrm{p}<0.001)$ and an unknown Gleason score (HR 10.59; 95\% CI 1.04-108; $\mathrm{p}=0.046$ ) had a higher risk of mortality compared to the reference category $2-6$. Yet, surgical margin status was not any longer significantly associated with prostate cancer-specific mortality.

\section{Discussion}

In the current study, we found that more aggressive tumour characteristics are responsible for both PSM after prostatectomy and worse prostate cancer-specific survival. Although, surgical margin status was associated with prostate cancer-specific survival in univariate analysis with PSM patients showing a doubled risk of dying as compared to NSM patients, this increased risk disappeared after adjusting for variables related to the gravity of the disease in the multivariate analysis. Yossepowitch 
Table 2 Multiadjusted comparison ${ }^{a}$ of sociodemographic, treatment and surgeon characteristics among prostate cancer patients after prostatectomy $(n=1$ '254) according to surgical margin status

\begin{tabular}{|c|c|c|c|c|c|c|}
\hline \multirow[t]{4}{*}{ Characteristics } & \multicolumn{4}{|c|}{ Surgical margin status } & \multirow{4}{*}{$\begin{array}{l}\text { Adjusted } \\
\text { Odds ratio } \\
(95 \% \mathrm{Cl})\end{array}$} & \multirow[t]{4}{*}{ P-value } \\
\hline & \multirow{2}{*}{\multicolumn{2}{|c|}{$\begin{array}{c}\text { Positive } \\
\text { (cases) } \\
\end{array}$}} & \multirow{2}{*}{\multicolumn{2}{|c|}{$\begin{array}{c}\text { Negative }^{\mathrm{b}} \\
\text { (controls) } \\
\end{array}$}} & & \\
\hline & & & & & & \\
\hline & $\mathrm{N}$ & $\%$ & $\mathrm{~N}$ & $\%$ & & \\
\hline \multicolumn{7}{|l|}{ Period } \\
\hline 1990-1994 & 29 & 50.0 & 29 & 50.0 & 1 & 0.025 \\
\hline 1995-1999 & 105 & 42.9 & 140 & 57.1 & $1.05(0.53-2.06)$ & \\
\hline $2000-2004$ & 201 & 40.8 & 292 & 59.2 & $1.47(0.73-2.99)$ & \\
\hline $2005-2008$ & 144 & 31.4 & 314 & 68.6 & $0.92(0.44-1.92)$ & \\
\hline \multicolumn{7}{|l|}{ Type of surgery } \\
\hline Perineal/Retropubic & 196 & 45.9 & 231 & 54.1 & 1 & 0.443 \\
\hline Laparoscopic & 62 & 39.2 & 96 & 60.8 & $0.96(0.61-1.53)$ & \\
\hline Robot-assisted & 35 & 32.1 & 74 & 67.9 & $0.96(0.55-1.69)$ & \\
\hline Unknown & 186 & 33.2 & 374 & 66.8 & $0.77(0.52-1.12)$ & \\
\hline \multicolumn{7}{|l|}{ Clinical T } \\
\hline сT0-сT1 & 83 & 31.8 & 178 & 68.2 & 1 & 0.038 \\
\hline cT2 & 163 & 35.7 & 293 & 64.3 & $0.93(0.65-1.31)$ & \\
\hline cT3 & 79 & 63.2 & 46 & 36.8 & $1.73^{*}(1.05-2.85)$ & \\
\hline cTx & 154 & 37.4 & 258 & 62.6 & $1.18(0.82-1.70)$ & \\
\hline \multicolumn{7}{|l|}{ Pathological T } \\
\hline pT0-pT2 & 239 & 27.5 & 629 & 72.5 & 1 & $<0.001$ \\
\hline рT3-рT4 & 240 & 62.2 & 146 & 37.8 & $2.68(2.00-3.59)$ & \\
\hline \multicolumn{7}{|l|}{ PSA level } \\
\hline $0-9$ & 217 & 32.8 & 445 & 67.2 & 1 & 0.036 \\
\hline $10-20$ & 98 & 51.0 & 94 & 49.0 & $1.52^{*}(1.06-2.17)$ & \\
\hline $21+$ & 57 & 64.0 & 32 & 36.0 & $1.80 *(1.06-3.05)$ & \\
\hline Unknown & 107 & 34.4 & 204 & 65.6 & $1.03(0.74-1.42)$ & \\
\hline \multicolumn{7}{|l|}{ Gleason } \\
\hline $2-6$ & 218 & 30.5 & 497 & 69.5 & 1 & $<0.001$ \\
\hline 7 & 195 & 45.2 & 236 & 54.8 & $1.61^{* * *}(1.23-2.12)$ & \\
\hline $8-10$ & 60 & 61.9 & 37 & 38.1 & $2.25^{* * *}(1.39-3.63)$ & \\
\hline Unknown & 6 & 54.5 & 5 & 45.5 & $1.87(0.46-7.71)$ & \\
\hline \multicolumn{7}{|l|}{ Tumour percentage $\mathrm{e}^{c}$} \\
\hline$\leq 10 \%$ & 202 & 26.7 & 554 & 73.3 & 1 & $<0.001$ \\
\hline$>10 \%$ & 252 & 57.9 & 183 & 42.1 & $2.90^{* * *}(2.21-3.81)$ & \\
\hline Unknown & 25 & 39.7 & 38 & 60.3 & $1.37(0.78-2.43)$ & \\
\hline Total & 479 & 38.2 & 775 & 61.8 & & \\
\hline
\end{tabular}

Geneva Cancer Registry 1990-2008.

a Logistic regression adjusted for all variables (clinical and pathological T status were entered separately, due to their co-linearity; the results presented derive from the model with clinical T).

${ }^{\mathrm{b}}$ Negative and close.

'Tumour percentage of the prostate was calculated as tumour volume divided by the prostate volume.

$\mathrm{Cl}$ : confidence interval.

${ }^{*} \mathrm{p}<0.05$; ${ }^{* * *} \mathrm{p}<0.001$. 


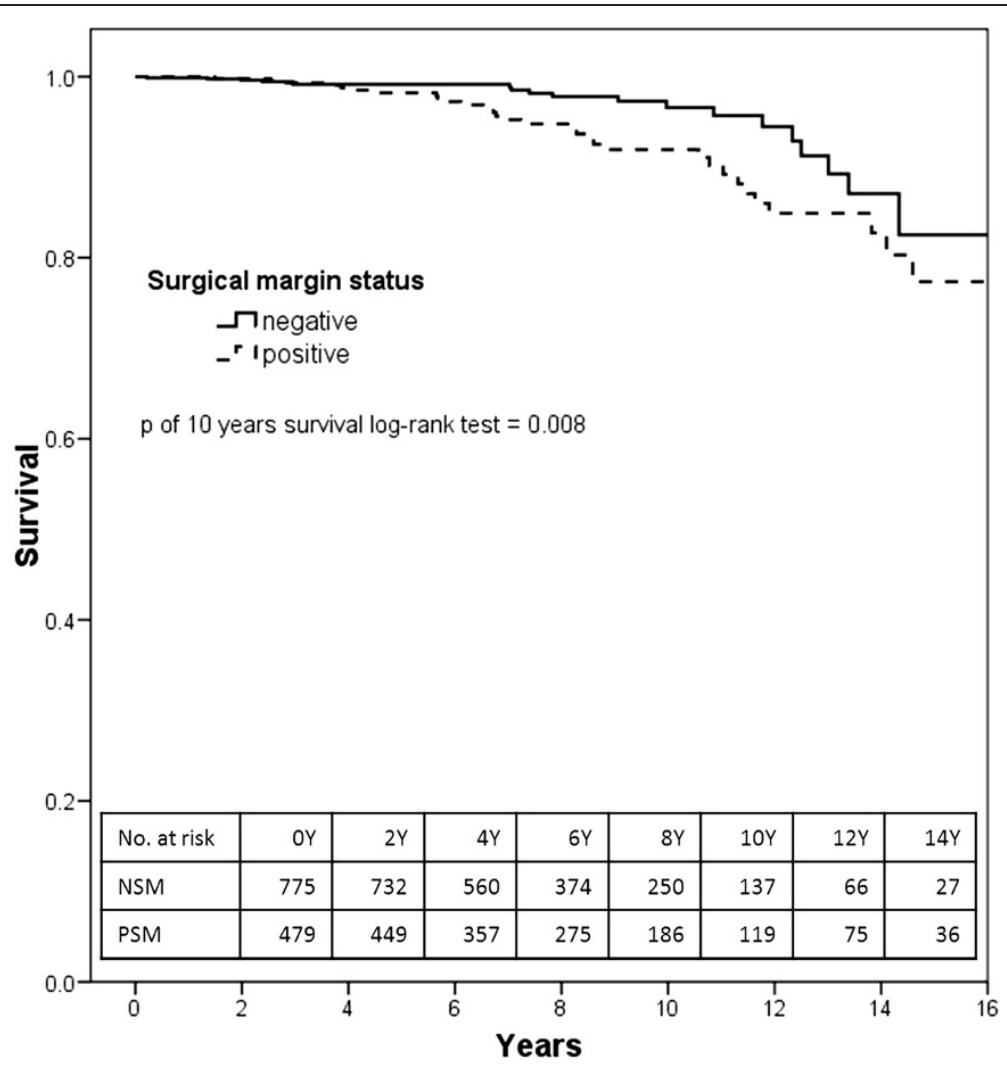

Figure 1 Kaplan Meier curve of the prostate cancer-specific survival among prostate cancer patients after radical prostatectomy according to surgical margin, Geneva Cancer Registry, 1990-2010. No. at risk: Numbers of persons at risk at the beginning of the period of follow-up. NSM: Negative Surgical Margin. PSM: Positive Surgical Margin.

et al., have recently published a systematic review of the literature covering the last ten years, on positive surgical margins after radical prostatectomy evaluating also their oncologic impacts [22]. The authors concluded that the long term impact of positive margins on cancer progression and specific survival is highly variable and largely dependent on additional risk modifiers. In fact, they noted that while all the revised studies showed a significant association between positive margins and biochemical recurrence, the data pertaining to metastatic progression and death were less consistent with only two studies indicating that PSMs were significantly associated with an increased risk of prostate cancer-specific mortality $[15,23]$. In the Surveillance, Epidemiology and End Results (SEER) data analysis, Wright et al., found a 2.6-fold increased unadjusted risk of prostate cancer-specific mortality that remained significant also after adjusting for grade, stage, additional radiotherapy, age, race, registry and year of diagnosis. However, when stratified by adverse pathological features of the tumour these findings held only for those with higher grade or pT3 tumours [15]. In a more recent study on a single surgeon cohort, Chalfin et al., showed that PSM had a statistically significant, but modest, adverse effect on prostate cancer-specific mortality in a model including Gleason score, year of surgery and pathological stage [23]. Similarly to these studies, in our study we found a strong association of prostate cancerspecific mortality with PSM in univariate analysis, however, this association disappeared in the multivariate analysis. Unlike these studies in our multivariate model we simultaneously adjusted for all the pathological adverse tumour features, including Gleason, stage, PSA level, percent of the tumour in the prostate, which emerged as the strongest predictors of mortality. Consistently with the results of another recent study, our results suggest that PSM alone does not increase the risk of dying from prostate cancer [24].

In the literature, surgical margins after prostatectomy are evaluated in different ways through different study designs. Population based studies are valuable designs mostly because of the large cohorts involved, however the accuracy is often not very high. After a systematic audit of the SEER registry, Shah et al., showed that 30\% of radical prostatectomies performed in 2007 were inaccurately coded, and concluded that clinicians and investigators should recognize the limitations of tumour registry data on PSM [25]. For the current study, we opened all the files and re-checked all parameters and 
Table 3 Prognostics factors of 10 years prostate cancer mortality derived from Cox regression analysis among prostate cancer patients with prostatectomy

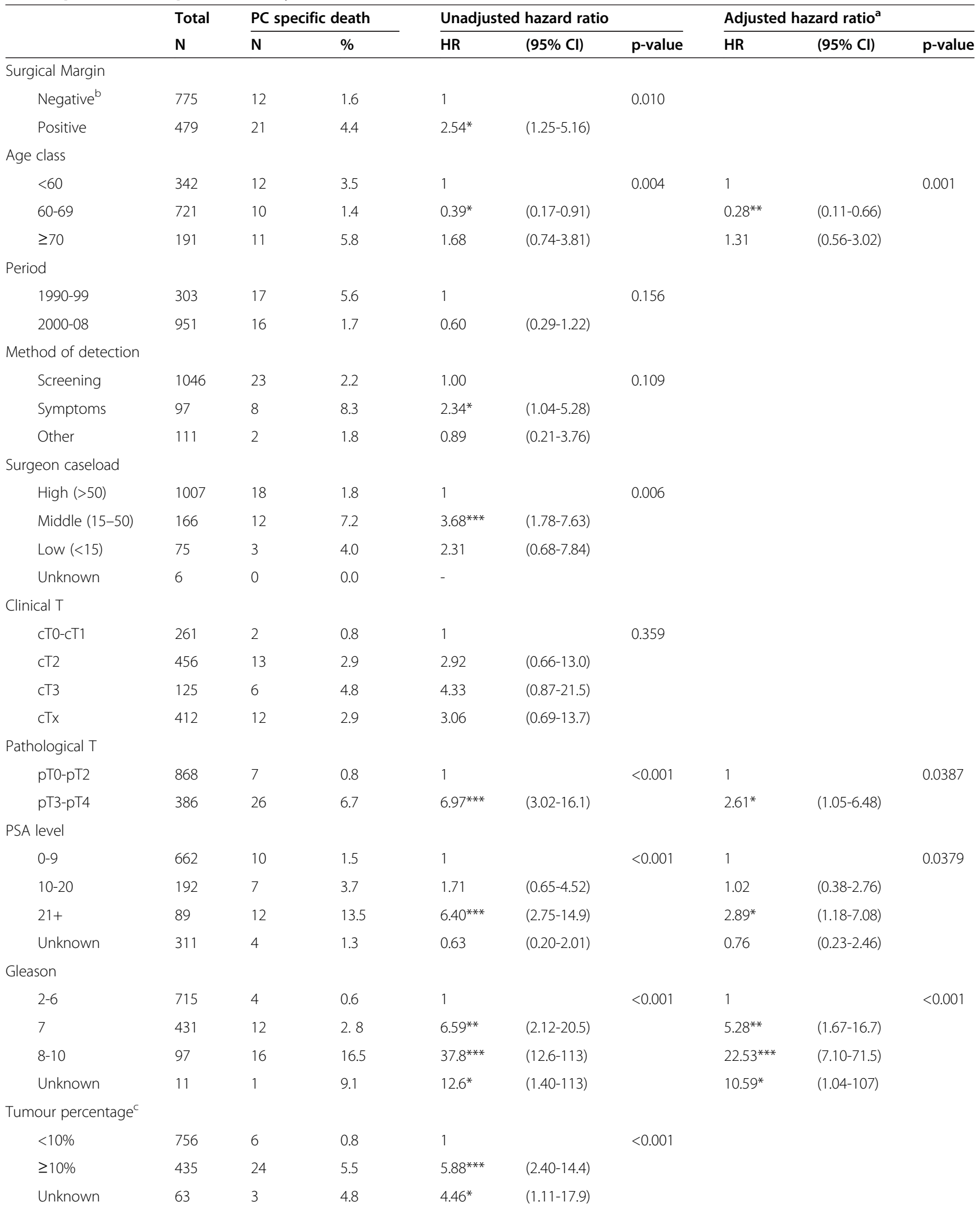


Table 3 Prognostics factors of 10 years prostate cancer mortality derived from Cox regression analysis among prostate cancer patients with prostatectomy (Continued)

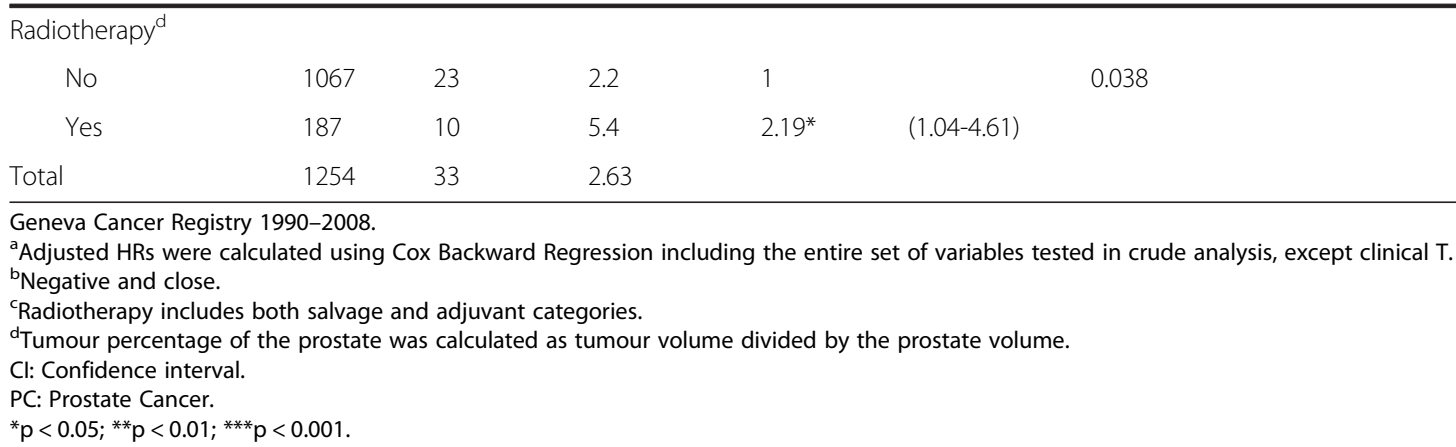

information, improving the accuracy of our compared to the available literature based on cancer registries. This could explain why the overall proportion of $38.2 \%$ PSM is higher, compared to the range found in other studies [5]. The proportion of PSM decreased during the study period, from $50 \%$ in $1990-1994$, to $31 \%$ in 2005-2008. Stage shift and surgeons at the end of the learning curve of prostatectomy, may explain the finding of significantly lower PSM rates in the later prostatectomies. In fact, we found that the ratio of cancer with pathological T0-T2/T3-T4 went from 0.7 in 1990-1994, to 3.4 in $2005-2008$ (test for trend $=54.58, \mathrm{p}<0.001$ ). On the other hand, we also observed in the univariate analysis that "closed" surgeries such as laparoscopic and robot-assisted surgeries yielded significantly less PSM, confirming the findings of Touijer et al. [26] However, for the cases treated in the private sector, the surgical procedure was not always reported. Also, most robotassisted surgeries reported in our study were performed in the public hospital by a selected group of surgeons. The number of deaths from prostate cancer in the groups of surgery procedures was too low to allow showing an association with survival.

The present study was a retrospective analysis with a relative short follow-up, which is the main limitation of the study. This could be the main reason for the absence of impact of PSM on PCSS. If we accept that BCR is a surrogate of PCSS, since the influence of PSM on BCR is well established, we could foresee that only a study with a median time of follow-up $>10$ years would be able to highlight PSM as a significant predictor of PCSS on a multivariate basis. However, we could not provide data regarding biochemical recurrences, as the Geneva Cancer Registry does not collect this information. Furthermore, the number of prostate cancer deaths was very low $(n=33$ at 10 year and $n=51$ at the end of follow-up), another possible reason for underpowered results. However, we observed similar survival rates in other studies $[14,15]$. Another limitation is the use of different pathology laboratories (private and public) in the area. This could have caused inter-observer variability, which was evident in the classification of close surgical margins: $72 \%$ were reported from the private pathology laboratory and $28 \%$ from the public laboratory. Because of the limited number of patients with close surgical margins, those patients were regrouped together with the negative surgical margins in further analyses, as already suggested in the literature [21]. Another limitation of the study is the relatively high percentage of patients lost to follow-up (12.2\%). This is peculiar to the Geneva canton, related to the fact that Geneva is an international city, with $43 \%$ of the population consisting of foreigners and a strong work-related migration rate. We compared the patients lost to follow-up to the rest of the study population and found no significant differences in terms of patient, tumour and treatment characteristics. Therefore, we find it unlikely that this selection could have strongly biased our results in terms of the impact of PSM on mortality. On the other hand, because $12 \%$ of the cohort was not at risk of prostate cancer mortality, the substantial number of patients who were lost to follow-up could be one of the reasons for the high specific survival rate that we observed. As we had only partial information on the presence of comorbidities, this variable was not included in our analysis. However, in this population comorbidities are expected to have had only a limited impact on survival as the population is younger and therefore healthier; among the 231 study patients for whom information on comorbidities was available, only $32 \%$ reported at least one comorbidity, as opposed to $51 \%$ of all prostate cancer patients aged $>65$ years in our registry. Another variable we did not include in the analyses, as available only since 2008, was the information about nerve-sparing approach, however, previous studies have shown that nerve-sparing procedures are safe and not associated with an increased positive margin rate nor on disease progression [27]. The strength of our study is that the population-based approach permits both to generalize the results to the whole population and to examine the effect of PSM in routine care. In addition, the re-opening of all the patients' files gave further strength to this study, 
since we were able to double-check and validate all the data. If we consider the context of data collection in a cancer registry, one could generally recommend, as recently stated by Raldow et al., that the extension of the treatment registration period from six to nine months or even one year, especially in the case of prostate cancer treatment, could be an advantage for future studies like this one [28]. Finally, in our analyses we could take into account of a large number of important prognostic factors for prostate cancer mortality.

Although the association between PSM and survival is not clear, the link with biochemical recurrence is well established [9-12]. Indeed, in the 2011 European Association of Urology guidelines, as well as the National Comprehensive Cancer Network (NCCN) guidelines, it has been recommended to take into account surgical margin status in the adjuvant treatment decision, as an independent risk factor for BCR $[29,30]$. In a recent publication, Lu et al., found that close surgical margins as well were independently associated with a twofold risk of postoperative biochemical recurrence and suggest that close margins might be an indicator of local recurrence, and therefore also be of relevance when considering salvage therapy [31]. To date only the SWOG 8794 trial with its long median follow-up could demonstrate improved overall survival with adjuvant radiation therapy in men with pT3a and/or positive margin disease in exploratory analysis. However, the differential effect of adjuvant radiotherapy vs early salvage radiotherapy was not evaluated in this trial, as salvage at PSA recurrence was not mandated by protocol in the observation arm ([32]). In a situation where the scientific evidence in favour of early $v s$. delayed use of radiotherapy to control local recurrence is still lacking, it seems reasonable to add the information on PSM to the other clinical prognostic variables in order to obtain a more comprehensive assessment of the individual risk [22].

\section{Conclusions}

To conclude, our data showed that surgical margins after prostatectomy are predominantly predicted by tumour characteristics, but are not independently associated with prostate cancer-specific survival. Aggressive tumour characteristics are correlated with both positive surgical margins after prostatectomy and worse prostate cancerspecific survival. These results should be considered for future research and when evaluating patients with a PSM for adjuvant and/or salvage therapy.

\section{Abbreviations}

PSM: Positive surgical margin; NSM: Negative surgical marigin; PCSS: Prostate cancer-specific survival; PSA: prostate specific antigen screening; BCR: Breast cancer recurrence; TNM: Tumour node metastasis; SD: Standard deviation; OR: Odds ratio; Cl: Confidence interval; HR: Hazard ratio; SEER: Surveillance, Epidemiology and End Results.
Competing interests

All the authors declare that they have no competing interests.

\section{Authors' contributions}

VR, ER performed and designed the research study; wrote the paper; $C B$ performed and designed the research study. MU analysed the data; INC contributed to the data collection; FS, GW, Cl and RM contributed to the design interpretation of the results and the redaction of the manuscript. All the authors have directly been involved in the review and approval of the manuscript.

\section{Acknowledgements}

We thank Mr Robin Schaffar and Mr Gérald Fioretta for their support in the statistical analysis; the professionals and patients of the Geneva prostate cancer research network; and Ms. Milena Uehlinger for her editorial assistance.

\section{Author details}

${ }^{1}$ Geneva Cancer Registry, Global Health Institute, University of Geneva, 55 Bd. de la Cluse, Geneva 1205, Switzerland. ${ }^{2}$ Urological Centre, Clinique des Grangettes, chemin des Grangettes 7, Chêne-Bougeries 1224, Switzerland. ${ }^{3}$ Department of Urology, Geneva University Hospitals, rue Gabrielle Perret-Gentil 4, Geneva 1205, Switzerland. ${ }^{4}$ Department of Radiation Oncology, Geneva University Hospitals, rue Willy Donzé 6, Geneva 1205, Switzerland.

Received: 18 June 2014 Accepted: 24 October 2014 Published: 5 November 2014

\section{References}

1. GLOBOCAN: v1.0, Cancer Incidence and Mortality Worldwide: IARC CancerBase No. 11. 2012. http://globocan.iarc.fr.

2. Holmstrom B, Johansson M, Bergh A, Stenman UH, Hallmans G, Stattin P: Prostate specific antigen for early detection of prostate cancer: longitudinal study. BMJ 2009, 339:b3537.

3. Bill-Axelson A, Holmberg L, Ruutu M, Garmo H, Stark JR, Busch C, Nordling S, Haggman M, Andersson SO, Bratell S, Spångberg A, Palmgren J, Steineck G, Adami HO, Johansson JE, SPCG-4 Investigators: Radical prostatectomy versus watchful waiting in early prostate cancer. N Engl J Med 2011, 364:1708-1717.

4. Wilt TJ, Brawer MK, Jones KM, Barry MJ, Aronson WJ, Fox S, Gingrich JR, Wei JT, Gilhooly P, Grob BM, Nsouli I, Iyer P, Cartagena R, Snider G, Roehrborn C, Sharifi R, Blank W, Pandya P, Andriole GL, Culkin D, Wheeler T, Prostate Cancer Intervention versus Observation Trial (PIVOT) Study Group: Radical prostatectomy versus observation for localized prostate cancer. N Engl J Med 2012, 367:203-213.

5. Han M, Partin AW, Chan DY, Walsh PC: An evaluation of the decreasing incidence of positive surgical margins in a large retropubic prostatectomy series. J Urol 2004, 171:23-26.

6. Coelho RF, Chauhan S, Orvieto MA, Palmer KJ, Rocco B, Patel VR: Predictive factors for positive surgical margins and their locations after robotassisted laparoscopic radical prostatectomy. Eur Urol 2010, 57:1022-1029.

7. Williams SB, D'Amico AV, Weinberg AC, Gu X, Lipsitz SR, Hu JC: Populationbased determinants of radical prostatectomy surgical margin positivity. BJU Int 2011, 107:1734-1740.

8. Vesey SG, McCabe JE, Hounsome L, Fowler S: UK radical prostatectomy outcomes and surgeon case volume: based on an analysis of the British Association of Urological Surgeons Complex Operations Database. BJU Int 2012, 109:346-354.

9. Berge V, Berg RE, Hoff JR, Wessel N, Svindland A, Karlsen SJ, Eri LM: Fiveyear progression-free survival in 577 patients operated on with laparoscopic radical prostatectomy for localized prostate cancer. Scand J Urol Nephrol 2012, 46:8-13

10. Albadine R, Hyndman ME, Chaux A, Jeong JY, Saab S, Tavora F, Epstein Jl, Gonzalgo ML, Pavlovich CP, Netto GJ: Characteristics of positive surgical margins in robotic-assisted radical prostatectomy, open retropubic radical prostatectomy, and laparoscopic radical prostatectomy: a comparative histopathologic study from a single academic center. Hum Pathol 2012, 43:254-260. 
11. Oh JJ, Hong SK, Byun SS, Choe G, Lee SE: Prognostic significance of positive surgical margins after radical prostatectomy among pT2 and pT3a prostate cancer. Urol Oncol 2013, 31:595-600.

12. Kim SC, Jeong I, Song C, Hong JH, Kim CS, Ahn H: Biochemical recurrencefree and cancer-specific survival after radical prostatectomy at a single institution. Kor J Urol 2010, 51:836-842.

13. Lewinshtein D, Teng B, Valencia A, Gibbons R, Porter CR: The association between pre-operative PSA and prostate cancer-specific mortality in patients with long-term follow-up after radical prostatectomy. Prostate 2012, 72:24-29.

14. Boorjian SA, Karnes RJ, Crispen PL, Carlson RE, Rangel LJ, Bergstralh EJ, Blute $\mathrm{ML}$ : The impact of positive surgical margins on mortality following radical prostatectomy during the prostate specific antigen era. $J$ Urol 2010, 183:1003-1009.

15. Wright JL, Dalkin BL, True LD, Ellis WJ, Stanford JL, Lange PH, Lin DW: Positive surgical margins at radical prostatectomy predict prostate cancer specific mortality. J Urol 2010, 183:2213-2218.

16. Ploussard G, Agamy MA, Alenda O, Allory Y, Mouracade P, Vordos D, Hoznek A, Abbou CC, de la TA, Salomon L: Impact of positive surgical margins on prostate-specific antigen failure after radical prostatectomy in adjuvant treatment-naive patients. BJU Int 2011, 107:1748-1754

17. Rubin MA, Maher CA, Chinnaiyan AM: Common gene rearrangements in prostate cancer. J Clin Oncol 2011, 29:3659-3668.

18. Chuang AY, Epstein Jl: Positive surgical margins in areas of capsular incision in otherwise organ-confined disease at radical prostatectomy: histologic features and pitfalls. Am J Surg Pathol 2008, 32:1201-1206.

19. TNM: Classification of Malignant Tumours. Oxford: Wiley-Blackwell; 2009.

20. Bates TS, Reynard JM, Peters TJ, Gingell JC: Determination of prostatic volume with transrectal ultrasound: a study of intra-observer and interobserver variation. J Urol 1996, 155:1299-1300.

21. Epstein Jl, Sauvageot J: Do close but negative margins in radical prostatectomy specimens increase the risk of postoperative progression? J Urol 1997, 157:241-243

22. Yossepowitch O, Briganti A, Eastham JA, Epstein J, Graefen M, Montironi R, Touijer K: Positive surgical margins after radical prostatectomy: a systematic review and contemporary update. Eur Urol 2014, 65:303-313.

23. Chalfin HJ, Dinizo M, Trock BJ, Feng Z, Partin AW, Walsh PC, Humphreys E, Han M: Impact of surgical margin status on prostate-cancer-specific mortality. BJU Int 2012, 110:1684-1689.

24. Stephenson AJ, Eggener SE, Hernandez AV, Klein EA, Kattan MW, Wood DP Jr, Rabah DM, Eastham JA, Scardino PT: Do margins matter? The influence of positive surgical margins on prostate cancer-specific mortality. Eur Urol 2013, 65:675-680.

25. Shah SK, Fleet TM, Williams V, Smith AY, Skipper B, Wiggins C: SEER coding standards result in underestimation of positive surgical margin incidence at radical prostatectomy: results of a systematic audit. J Urol 2011, 186:855-859.

26. Touijer K, Kuroiwa K, Eastham JA, Vickers A, Reuter VE, Scardino PT, Guillonneau B: Risk-adjusted analysis of positive surgical margins following laparoscopic and retropubic radical prostatectomy. Eur Urol 2007, 52:1090-1096.

27. Alkhateeb SS, Alibhai SM, Finelli A, Fleshner NE, Jewett MA, Zlotta AR, Trachtenberg J: Does nerve-sparing radical prostatectomy increase the risk of positive surgical margins and biochemical progression? Urol Annu 2010, 2:58-62.

28. Raldow AC, Presley CJ, Yu JB, Sharma R, Cramer LD, Soulos PR, Long JB, Makarov DV, Gross CP: The relationship between clinical benefit and receipt of curative therapy for prostate cancer. Arch Intern Med 2012, 172:362-363.

29. Heidenreich A, Bellmunt J, Bolla M, Joniau S, Mason M, Matveev V, Mottet N, Schmid HP, van der KT, Wiegel T, Zattoni F, European Association of Urology: EAU guidelines on prostate cancer: part 1: screening, diagnosis, and treatment of clinically localised disease. Eur Urol 2011, 59:61-71.

30. National Comprehensive Cancer Network (NCCN ${ }^{\circledR}$ ) Prostate Cancer version 2.2014. www.ncen.org.
31. Lu J, Wirth GJ, Wu S, Chen J, Dahl DM, Olumi AF, Young RH, McDougal WS, Wu CL: A close surgical margin after radical prostatectomy is an independent predictor of recurrence. J Urol 2012, 188:91-97.

32. Thompson IM, Tangen CM, Paradelo J, Lucia MS, Miller G, Troyer D, Messing E, Forman J, Chin J, Swanson G, Canby-Hagino E, Crawford ED: Adjuvant radiotherapy for pathological T3NOM0 prostate cancer significantly reduces risk of metastases and improves survival: long-term followup of a randomized clinical trial. J Urol 2009, 181:956-962

doi:10.1186/1471-2490-14-86

Cite this article as: Retèl et al:: Determinants and effects of positive surgical margins after prostatectomy on prostate cancer mortality: a population-based study. BMC Urology 2014 14:86.

\section{Submit your next manuscript to BioMed Central and take full advantage of:}

- Convenient online submission

- Thorough peer review

- No space constraints or color figure charges

- Immediate publication on acceptance

- Inclusion in PubMed, CAS, Scopus and Google Scholar

- Research which is freely available for redistribution

Submit your manuscript at www.biomedcentral.com/submit
C BioMed Central 